\title{
mHealth Interventions for Treatment Adherence and Outcomes of Care for Cardiometabolic Disease Among Adults Living With HIV: Systematic Review
}

Oluwakemi Ololade Odukoya ${ }^{1}$, MPH, MSc, MD; Chidumga Ohazurike ${ }^{2}$, MPH, MD; Maxwell Akanbi ${ }^{3}$, MSCI, MD, $\mathrm{PhD}$; Linda C O'Dwyer ${ }^{4}$, MA, MSLIS; Brenda Isikekpei ${ }^{2}$, MD; Ewemade Kuteyi ${ }^{2}$, MD; Idaomeh O Ameh ${ }^{5}$, MD; Olanlesi Osadiaye $^{2}$, MPH, MD; Khadijat Adebayo ${ }^{6}$, MD; Adewunmi Usinoma ${ }^{2}$, MPH, MD; Ajoke Adewole ${ }^{2}$, MPH, $^{2}$ MD; Nkiruka Odunukwe ${ }^{7}$, MD; Kola Okuyemi ${ }^{8}$, MD; Andre Pascal Kengne ${ }^{9}$, MD

\footnotetext{
${ }^{1}$ Department of Community Health and Primary Care, College of Medicine, University of Lagos, Lagos, Nigeria

${ }^{2}$ Department of Community Health, Lagos University Teaching Hospital, Lagos, Nigeria

${ }^{3}$ Department of Preventive Medicine, Feinberg School of Medicine, Northwestern University, Chicago, IL, United States

${ }^{4}$ Galter Health Sciences Library and Learning Center, Feinberg School of Medicine, Northwestern University, Chicago, IL, United States

${ }^{5}$ Division of Nephrology, Zenith Medical and Kidney Center, Abuja, Nigeria

${ }^{6}$ Department of Clinical Medicine, All Saints University School of Medicine, Roseau, Dominica

${ }^{7}$ Non-Communicable Disease Research Group, Nigeria Institute of Medical Research, Lagos, Nigeria

${ }^{8}$ Department of Family and Preventive Medicine, University of Utah School Of Medicine, Salt Lake City, UT, United States

${ }^{9}$ Non-Communicable Disease Research Unit, Medical Research Council, Cape Town, South Africa
}

\section{Corresponding Author:}

Oluwakemi Ololade Odukoya, MPH, MSc, MD

Department of Community Health and Primary Care

College of Medicine

University of Lagos

\#16 Ishaga Road, Idi-Araba

Lagos, PMB 12003

Nigeria

Phone: 2348023200770

Email: drolukemiodukoya@yahoo.com

\section{Abstract}

Background: The success of antiretroviral therapy has led to an increase in life expectancy and an associated rise in the risk of cardiometabolic diseases (CMDs) among people living with HIV.

Objective: Our aim was to conduct a systematic review to synthesize the existing literature on the patterns of use and effects of mobile health (mHealth) interventions for improving treatment adherence and outcomes of care for CMD among people living with HIV.

Methods: A systematic search of multiple databases, including PubMed-MEDLINE, Embase, CINAHL, Scopus, Web of Science, African Journals online, ClinicalTrials.gov, and the World Health Organization Global Index Medicus of peer-reviewed articles, was conducted with no date or language restrictions. Unpublished reports on mHealth interventions for treatment adherence and outcomes of care for CMD among adults living with HIV were also included in this review. Studies were included if they had at least 1 component that used an mHealth intervention to address treatment adherence or 1 or more of the stated outcomes of care for CMD among people living with HIV.

Results: Our search strategy yielded 1148 unique records. In total, 10 articles met the inclusion criteria and were included in this review. Of the 10 studies, only 4 had published results. The categories of mHealth interventions ranged from short messaging, telephone calls, and wearable devices to smartphone and desktop web-based mobile apps. Across the different categories of interventions, there were no clear patterns in terms of consistency in the use of a particular intervention, as most studies $(9 / 10$, 90\%) assessed a combination of mHealth interventions. Short messaging and telephone calls were however the most common interventions. Half of the studies $(5 / 10,50 \%)$ reported on outcomes that were indirectly linked to CMD, and none of them provided 
reliable evidence for evaluating the effectiveness of mHealth interventions for treatment adherence and outcomes of care for CMD among people living with HIV.

Conclusions: Due to the limited number of studies and the heterogeneity of interventions and outcome measures in the studies, no definitive conclusions could be drawn on the patterns of use and effects of mHealth interventions for treatment adherence and outcomes of care for CMD among people living with HIV. We therefore recommend that future trials should focus on standardized outcomes for CMD. We also suggest that future studies should consider having a longer follow-up period in order to determine the long-term effects of mHealth interventions on CMD outcomes for people living with HIV.

Trial Registration: PROSPERO International Prospective Register of Systematic Reviews CRD42018086940; https://www.crd.york.ac.uk/prospero/display_record.php?ID=CRD42018086940

(JMIR Mhealth Uhealth 2021;9(6):e20330) doi: $\underline{10.2196 / 20330}$

\section{KEYWORDS}

mHealth; HIV; cardiometabolic disease; text messaging; mobile; systematic review; telephone calls; wearable devices; smartphones; desktop; web-based; mobile apps

\section{Introduction}

Cardiometabolic diseases (CMDs) represent a huge threat to the global progress that has been achieved in reducing mortality and morbidity among people living with HIV [1,2]. With the successes of antiretroviral therapies (ARTs), there has been increased life expectancy and a reduction in the burden of opportunistic infections among people living with HIV [3-5]. However, both HIV and ART are independently associated with an increased risk of CMD [6-8]. The incidence of CMD among people living with HIV ranges from 1.19 per 1000 person-years to 11.3 per 1000 person-years $[9,10]$. People living with HIV show consistent patterns of increased risk for diabetes [11-13], stroke [14], sudden cardiac death [15], heart failure [16], coronary heart disease, and myocardial Infarction [17-19]. Furthermore, established CMD risk factors like tobacco smoking and alcohol use are prevalent among people living with HIV [20,21].

The use of mobile technology, especially the use of mobile phones, has increased tremendously worldwide. The majority of the over 7 billion mobile phone users reside in low- and middle-income countries (LMICs), where the burden of HIV and AIDS is the heaviest [22]. The improved access to mobile technology presents an immense opportunity for promoting the health of people living with HIV, and mobile technology is increasingly being used to provide support for people living with HIV and promote adherence to ART [23-25].

Research on CMD among people living with HIV has increased significantly over the last 2 decades, and significant proportions of these studies have assessed the use of mobile health (mHealth) interventions to promote HIV care [7-12]. Systematic reviews on the topic have shown that most research in this field focuses on mobile phone interventions that aim to promote ART adherence and other forms of direct HIV and AIDS outcomes [25-30]. In a paper that systematically reviewed mobile phone SMS text messaging interventions for HIV and other chronic diseases, many of the studies with chronic disease outcomes did not include people living with HIV [30]. Thus, the evidence for analyzing the patterns of use and effects of mHealth interventions for CMD outcomes among people living with HIV remains unclear. This review aims to synthesize existing literature on the patterns of use and effects of mHealth interventions for treatment adherence and outcomes of care for CMD among adults living with HIV.

\section{Methods}

\section{Study Design}

For this review, we followed the guidelines from the PRISMA (Preferred Reporting Items for Systematic reviews and Meta-Analyses) Statement [31]. The study protocol was also registered with the International Prospective Register of Systematic Reviews (trial ID number: CRD42018086940). We relied on data obtained from other studies that conducted primary research; therefore, obtaining institutional ethical approval was not required. We made use of deidentified data that were stored in a password-protected database. We ensured that the data presented in this systematic review did not violate the privacy of the patients.

\section{Eligibility Criteria}

\section{Inclusion Criteria}

To ensure that we captured all articles that described patterns of existing mHealth interventions for CMD outcomes, we did not limit our search by study type or design. We included studies that described any mHealth interventions if the following criteria were met: (1) the study was conducted among adults aged $\geq 18$ years living with HIV; (2) the study involved the use of mobile phones or had any mHealth components embedded in its design; and (3) the study was designed to influence adherence to treatment or outcomes of care for 1 or more CMD (ie, hypertension, dyslipidemia, obesity, stroke, coronary heart disease, diabetes mellitus, and metabolic syndrome). Articles published in any language with English abstracts were eligible for inclusion.

\section{Exclusion Criteria}

A study was excluded if (1) it was an opinion piece, (2) it was a publication that lacked primary data, and (3) it had no explicit method description. In the case of duplicate publications of the same material in more than 1 journal or conference proceeding, the most complete and recent version was used. 


\section{Definitions}

The diagnosis of HIV was based on positive reports from screening tests or participants' self-reported doctor diagnoses. The CMDs reviewed included hypertension, diabetes mellitus, dyslipidemia, obesity, stroke, coronary heart disease, and metabolic syndrome. This study was a systematic review for which no primary data were collected. The diagnosis of HIV and cardiometabolic outcomes were based on reports from the studies included in this review.

The outcome measures included differences in adherence to treatment or outcomes relating to any of the listed CMDs; differences in mortality due to the listed CMDs; differences in blood pressure, glycemic control, and blood lipid levels; and reductions in CMD risk or BMI waist circumference and waist-hip ratios.

With regard to mHealth, for the purpose of this review, we used the Global Observatory for eHealth definition, which defines mHealth as a medical and public health practice supported by mobile devices, such as mobile phones, patient monitoring devices, PDAs, and other wireless devices. mHealth involves the use and capitalization of a mobile phone's core utility in terms of voice messaging services and SMSs as well as more complex functionalities and applications, including general packet radio services, third and fourth generation mobile telecommunications (3G and 4G systems), GPSs, and Bluetooth technology [32].

\section{Search Strategy for the Identification of Relevant Studies}

Electronic searches of the following databases were conducted from inception to September 2019: PubMed-MEDLINE, Embase, CINAHL, Scopus, Web of Science, Cochrane Central Register of Controlled Trials, Global Health (Elton B. Stephens Company), the Institute of Electrical and Electronics Engineers, African Journals online, the Association for Computing Machinery, World Health Organization (WHO) reports, ClinicalTrials.gov, The Pan African Clinical Trials Registry and mHealth alliance, and the WHO Global Index Medicus. The search terms used included HIV-related terms (eg, HIV infections, HIV, HIVIAIDS, HIV-positive, and HIV infected), mobile device-related terms (eg, mobile health, mHealth, mobile phone, and short message) and CMD-related terms (eg, Hypertension, Diabetes, stroke, metabolic syndrome, and cardiometabolic). No language, publication type, or date limits were applied to the initial searches. The first author (OOO) and the librarian (LO) collaboratively developed the search strategy. The full list of search strategies is available in Multimedia Appendix 1.

\section{Reference Lists and Grey Literature}

We searched for additional relevant articles in the reference lists of the retrieved key articles and reviews. We contacted authors of included studies to acquire other data related to our outcomes of interest that may have been unpublished, informally published, or undergoing ongoing analysis. Principal investigators of registered clinical trials whose published results were not found within our search were contacted by email to share their results.

\section{Data Collection and Processing}

Search results were saved into EndNote (Clarivate Analytics) files by the librarian (LO). All EndNote files were deduplicated, collated, and transferred into Rayyan (Rayyan Systems Incorporated) [33] for subsequent processing. A pilot screen of 100 articles was performed by each reviewer to ensure the consistent interpretation of the inclusion and exclusion criteria. Two sets of reviewers (set 1: BI and KA; set 2: OO and OU) conducted an initial independent screening and eligibility assessment of articles' titles and abstracts by using the predefined inclusion and exclusion criteria. A third reviewer (OOO) resolved disagreements. Full-text copies of the selected articles were obtained for further review and assessed using the same process as the title and abstract screens. The flowchart for the study selection process is shown in Figure 1. Two independent reviewers (BI and $\mathrm{OO}$ ) used a pretested data extraction form that was adapted from the Cochrane data extraction template for intervention reviews of randomized controlled trials (RCTs) and non-RCTs [34] (Multimedia Appendix 2) to extract the data from the full texts [35-38]. The information extracted included the study title, author, year, country, study design, sample size, study population and setting, intervention type and delivery, components of the intervention, concurrent non-mHealth interventions or medications (if any), duration of intervention, cardiometabolic outcome, and secondary outcome measures. The results were synthesized and presented as a narrative synthesis of the details regarding the study type, intervention characteristics, study outcomes, and location. Due to the limited number of studies and the wide variability in the outcome measures, we were unable to perform a meta-analysis. 
Figure 1. PRISMA (Preferred Reporting Items for Systematic Reviews and Meta-Analyses) flowchart. CMD: cardiometabolic disease.

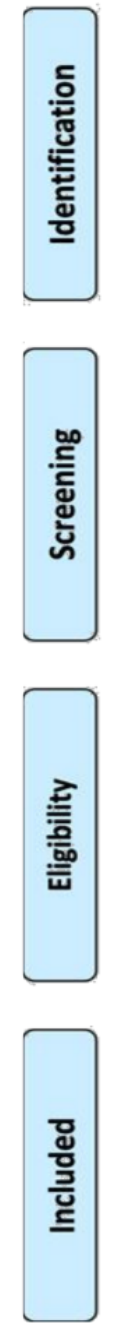

\section{Methodological Quality of Included Studies}

The quality of included studies was assessed by using the Cochrane risk of bias assessment tool [39]. Specifically, we assessed the quality of each included study by using the criteria from the seven domains of the tool (ie, random sequence generation, the blinding of study participants and key personnel, the blinding of the outcome assessment, selective outcome reporting, allocation concealment, incomplete outcome data, and the presence of bias from other sources) [39]. For each of these domains, each study was identified as having a low, high, or unclear risk. In total, 2 studies did not report on the blinding of the outcome assessment [35,36], while 3 studies had incomplete outcome data $[35,36,38]$. Two investigators (BI and $\mathrm{OO})$ independently assessed the quality of included studies, and a third reviewer (OOO) resolved discrepancies.

\section{Results}

\section{Included Studies}

Our search yielded 1148 unique records, of which 1129 were excluded for the reasons specified in Figure 1. Most of the excluded records $(1129 / 1148,98.34)$ were not related to mHealth, not related to our CMD outcomes of interest, or not conducted among people living with HIV. Of the 19 articles that were fully reviewed, 4 were unrelated to the CMD outcomes of interest, 3 were not about mHealth interventions, 1 was not conducted among people living with HIV, and 1 was a duplicate study. In total, 10 articles met the inclusion criteria.

The 10 included studies and their key study characteristics are summarized in Table 1. Of these included studies, 7 were RCTs [35,36,40-43]. In 90\% (9/10) of studies, study participants only included people living with HIV. The remaining $10 \%$ of studies included a combination of both people living with HIV and people living without HIV. Most studies (4/10, 40\%) had an average study period of about 12 months [36,37,40,43]. It is noteworthy that 6 of the 10 included studies were registered clinical trials that had unpublished results at the time of conducting this review [40-45]. The principal investigators of the included registered clinicals trials were contacted in order to ascertain the progress of the trials; however, no response was received at the time of concluding this review. The number of studies with unpublished results and the variation in outcomes across studies made it difficult to conduct a meta-analysis. 
Table 1. Summary of the key characteristics of included studies $(\mathrm{N}=10)$.

\begin{tabular}{|c|c|c|c|c|c|}
\hline $\begin{array}{l}\text { Study (author, } \\
\text { year, country) }\end{array}$ & $\begin{array}{l}\text { Study design and } \\
\text { methods }\end{array}$ & Inclusion criteria & Interventions & Outcomes & Reported results \\
\hline $\begin{array}{l}\text { Morillo-Verdugo } \\
\text { et al [36], 2018, } \\
\text { Spain }\end{array}$ & $\begin{array}{l}\text { Randomized con- } \\
\text { trolled trial }\end{array}$ & $\begin{array}{l}\text { Aged }>35 \text { years; on an- } \\
\text { tiretroviral therapy with } \\
\text { at least } 1 \text { drug pre- } \\
\text { scribed for the treat- } \\
\text { ment of hypertension, } \\
\text { dyslipidemia, angina } \\
\text { pectoris, cardiovascular } \\
\text { prophylaxis, or type } 2 \\
\text { diabetes mellitus; and } \\
\text { at a moderate or high } \\
\text { risk of cardiovascular } \\
\text { disease }\end{array}$ & $\begin{array}{l}\text { Periodic text mes- } \\
\text { sages on mobile } \\
\text { phones }\end{array}$ & $\begin{array}{l}\text { Cardiovascular risk index, } \\
\text { smoking reduction, blood } \\
\text { pressure control, and medica- } \\
\text { tion adherence }\end{array}$ & $\begin{array}{l}20.7 \% \text { of patients in the in- } \\
\text { tervention group vs } 12.5 \% \\
\text { of patients in the control } \\
\text { group reduced their Framing- } \\
\text { ham risk score from } \\
\text { high/very high to moder- } \\
\text { ate/low }(P=.02) \text {, and the } \\
\text { number of patients with } \\
\text { controlled blood pressure } \\
\text { increased by } 32.1 \%(P=.01) \text {. } \\
37.9 \% \text { of patients overall } \\
\text { stopped smoking }(P=.001) \text {. }\end{array}$ \\
\hline
\end{tabular}

Anglada-Mar- Single-arm, tinez et al [35], prospective pre2016, Spain and postintervention study

Roos et al [37], Randomized con2014, South Africa
Patients on treatment for heart failure, hypertension, or dyslipidemia for $>1$ month and those aged $>18$ years

On antiretroviral thera- Pedometer, activity py for $>6$ months, aged diary that included 20-65 years, ambulato- education materials ry without assistive de- and documents for vice, and had an elevat- self-monitoring, and ed risk of ischemic 1 monthly cell phone heart disease SMS message for motivation

Medplan smartphone app and weekly motivational messages
Medication adherence, cholesterol, triglycerides, and blood pressure control

The pedometer step count of both groups improved significantly.
Aged $>18$ years and had

HIV and type 2 diabetes mellitus

Grinspoon [40], Randomized case 2006, United States of America
Randomized case Aged 18 to 65 years control study and had 3 of the follow-

ing 5 characteristics: (1) waist circumferences of $>102 \mathrm{~cm}$ (40 in) for men and $>88 \mathrm{~cm}$ (35 in) in women; (2) triglyceride levels of $\geq 150$ $\mathrm{mg} / \mathrm{dL}$ or current antilipolytic drug treatment; (3) high-density lipoprotein levels of $<40 \mathrm{mg} / \mathrm{dL}$ for men and $<50 \mathrm{mg} / \mathrm{dL}$ for women; (4) blood pressure of $\geq 130 / 85 \mathrm{mmHg}$ or current antihypertensive drug treatment; and (5) fasting glucose level of $\geq 110 \mathrm{mg} / \mathrm{dL}$ 6-hour educational in- Diabetes self-management struction implemented skills and knowledge about as 2 3-hour meetings HIV or diabetes followed byweekly telephone support calls for 6 weeks

1-time counseling session with nutrition staff at the baseline visit and monthly unscripted phone calls

Waist-hip ratios and cardiovascular indices (total cholesterol; low-density lipoprotein, high-density (n) lipoprotein, and triglyceride cholesterol levels; blood pressure; cardiac enzymes; C-reactive protein; tissue plasminogen activator; plasminogen activator inhibitor; insulin; and glucose metabolism)

The proportion of missed doses decreased significantly for patients using the Medplan app $(P<.05)$. There was no difference in the health outcomes of patients.

The pedometer step counts of the control and intervention groups improved significantly $(P=.03$ for both groups) at 6 months, but this improvement was not significant at 12 months $(P=.33$ and $P=.21$, respectively). Significant between-group effects were observed in 6minute walk test distances $(P=.01)$, waist-to-hip ratios $(P<.01)$, glucose levels $(P<.01)$, and high-density lipoprotein levels $(P<.01)$ over the 12-month period.

There was a $34 \%$ increase in diabetes self-management skills from pretest to posttest, but there were no changes in knowledge about HIV or diabetes.

The results of the study have yet to be published. 


\begin{tabular}{|c|c|c|c|c|c|}
\hline $\begin{array}{l}\text { Study (author, } \\
\text { year, country) }\end{array}$ & $\begin{array}{l}\text { Study design and } \\
\text { methods }\end{array}$ & Inclusion criteria & Interventions & Outcomes & Reported results \\
\hline $\begin{array}{l}\text { Jaggers et al [41], } \\
2013 \text {, United } \\
\text { States of America }\end{array}$ & $\begin{array}{l}\text { Randomized con- } \\
\text { trolled trial }\end{array}$ & $\begin{array}{l}\text { Aged }>18 \text { years, had a } \\
\text { sedentary lifestyle, had } \\
\text { a viral load of }>75 \\
\text { copies/mL, was capable } \\
\text { of performing required } \\
\text { exercise regimen, and } \\
\text { had daily access to a } \\
\text { telephone for approxi- } \\
\text { mately } 10 \text { months }\end{array}$ & $\begin{array}{l}\text { Home-based physical } \\
\text { activity intervention: } \\
\text { The intervention in- } \\
\text { cluded a } 60 \text {-min, indi- } \\
\text { vidual, face-to-face } \\
\text { session; telephone } \\
\text { counselling calls; and } \\
\text { educational work- } \\
\text { books and pedometers } \\
\text { for the self-monitor- } \\
\text { ing of physical activi- } \\
\text { ty. }\end{array}$ & $\begin{array}{l}\text { The effect of the interven- } \\
\text { tion in terms of decreasing } \\
\text { modifiable risk factors and } \\
\text { increasing physical activity } \\
\text { among people living with } \\
\text { HIV and the effect of the in- } \\
\text { tervention in terms of de- } \\
\text { creasing modifiable risk } \\
\text { factors, such as fat distribu- } \\
\text { tion, blood lipids, and car- } \\
\text { diorespiratory fitness out- } \\
\text { comes, were assessed. }\end{array}$ & $\begin{array}{l}\text { The findings of the study } \\
\text { have yet to be published. }\end{array}$ \\
\hline
\end{tabular}

Brooke [42], Randomized con- People living with HIV Personalized, automat2017, United trolled trial

States of America ed, interactive mobile phone text message intervention

Aged $>30$ years, was

Dodson et al [43], 2016, Australia
Cluster randomized controlled trial participating doctor,

Health map website for (1) routine clinic visits involving the was not diagnosed with cardiovascular disease, and had not participated previously in an HIVspecific self- management or coaching program

Oduor et al [44], Contextual user in2018, Kenya terviews

Randomized con-

Kengne [45], 2019, South trolled trial
Patients living with HIV and hypertension

Adult South Africans with comorbid HIV and saging hypertension sharing of health records with a doctor; (2) access to own health record and information from home; (3) access to telephone and web-based self-management support; and (4) access to a peer-moderated, web-based group chat program.

Integrated desktop and mobile app

Automated text mesAfrica
Physical activity and dietary assessments; polyunsaturated fatty acids, carotenoids, and other biomarkers in plasma; and total cholesterol, triglyceride, and highand low-density cholesterol

10-year risk of nonfatal or coronary heart disease death, as estimated by a Framingham Heart Study risk equation and the Positive and Active Engagement in Life Scale from the Health Education Impact Questionnaire

The study is still ongoing.

The findings of the study have yet to be published.

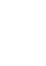

Improved efficacy, safety, and personalization of medication prescription
Mean difference in systolic The results of this study and diastolic blood pressure have yet to be published. at baseline and follow-up, uptake and adherence to blood pressure medications, mean change in lipid vari- ables, and mean change in adiposity variables

All included studies had an mHealth component, although some studies used a multimethod mHealth intervention approach, wherein support telephone calls were combined with educational instructions $[38,41]$ or the use of mobile phone apps were combined with user interviews [44]. However, short messaging $[36,37,42,45]$ and telephone calls $[38,40,41,43]$ were the most common mHealth interventions. Furthermore, 2 studies used mobile apps as their mHealth intervention component [35,44].

Although studies had varied outcomes, most had treatment adherence $(1 / 10,10 \%)$ [44], cardiometabolic outcomes $(5 / 10$, $50 \%)[37,40-43]$, or both $(3 / 10,30 \%)[35,36,45]$ as their primary or secondary study outcomes. The other studies had a combination of other outcomes that were not limited to treatment adherence or cardiometabolic outcomes, such as physical activity and the self-management of diabetes $[38,42]$.
With regard to the function of mHealth interventions, 4 studies used mHealth for medication adherence purposes [35,36,44,45], 3 studies used mHealth to improve physical activity and thereby reduce cardiovascular risk [37,41,42], 2 used mHealth for health promotion and health coaching purposes to reduce cardiovascular risk [37,38], and 1 used mHealth for the self-management of diabetes mellitus [38].

The majority of the studies $(9 / 10,90 \%)$ were conducted in hospital or clinic settings [35-38,40-43,45], whereas $10 \%(1 / 10)$ of the studies were conducted in a community setting in a rural area [44]. Furthermore, most of the studies were conducted in the high-income countries of Spain $(2 / 10,20 \%)$, the United States of America (4/10, 40\%), and Australia (1/10, 10\%). Only 3 studies were conducted in the LMICs of South Africa and 
Kenya in Sub-Saharan Africa, where the burden of HIV is quite significant.

\section{Effectiveness of mHealth Interventions}

With regard to the effects of mHealth interventions on treatment adherence and cardiometabolic outcomes in the 4 studies with published results, 2 studies reported a decrease in cardiovascular risk [36,37] and significant group effects for cardiometabolic outcomes, such as those on glucose level and high-density lipoproteins, between intervention and control groups [37]. In total, 1 study reported a $34 \%$ increase in diabetes self-management skills among participants [38], and 1 study reported no differences in effects on treatment adherence among study participants [35].

\section{Assessing the Risk Of Bias}

Figure 2 shows the assessment of the risk of bias in the included studies.

Figure 2. Cochrane risk of bias assessment [35-38].

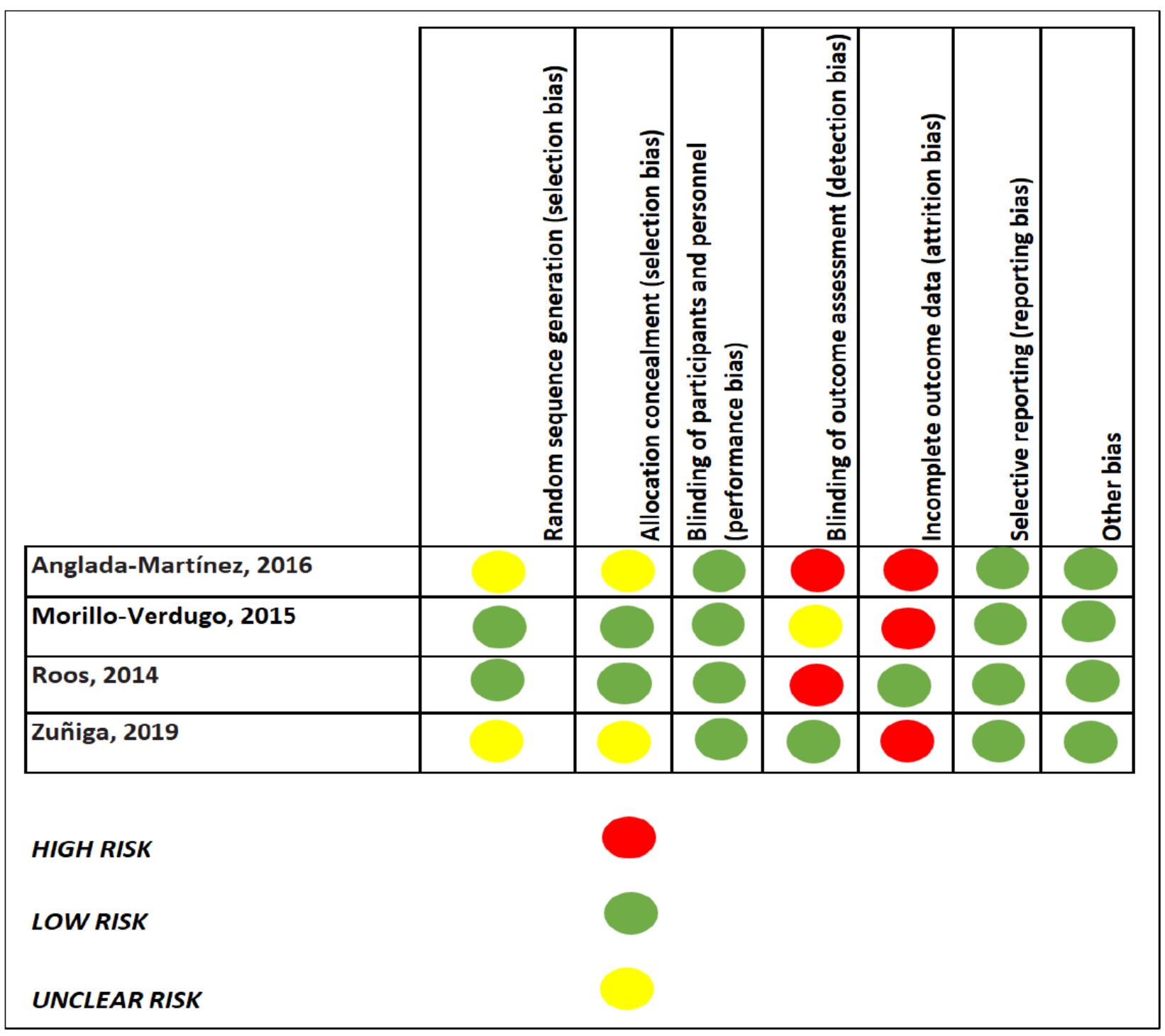

\section{Selection Bias (Random Sequence Generation and Allocation Concealment)}

Among the 10 included studies, the assessment of bias was conducted in only the 4 studies that were completed (Anglada-Martinez et al [35], Morillo-Verduogo et al [36], Roos et al [37], and Zuniga et al [38]). In the study by Morillo-Verduogo et al [36], the participants were randomized into control and intervention groups with a specific software that was used to generate a sequence of random numbers. Roos et al [37] used a simple randomization formula in Microsoft Excel 2010 for randomization. The method for selecting participants was unclear in the study by Anglada-Martinez et al [35], as the patients were followed during the preintervention phase in accordance with their usual schedule. Zuniga et al [38] selected 25 participants by using a convenient sampling method. This was because the Zuniga et al [38] study had to be completed in 12 months due to the guidelines of their funding mechanism as well as the constraints from budget limitations. During the allocation of participants, Roos et al [37] used an academic who was not directly involved in the study to carry out allocation concealment via sequentially numbered envelopes. In the studies by Zuniga et al [38] and Anglada-Martinez et al [35], allocation concealment was not carried out for participants. 
This was because the Zuniga et al [38] study was a single-group study with a pre- and posttest study design, and in the Anglada-Martinez et al [35] study, the sequence generation was not described.

\section{Performance and Detection Bias (Blinding of Participants, Personnel, and the Outcome Assessment)}

Only 1 out of the 4 completed studies carried out blinding, and this was the blinding of the study personnel. In that study the research assistant performed all of the assessments and was blinded to the group allocation. The assessment forms were also coded to ensure anonymity, and the first author conducted the intervention [37].

The studies by Anglada-Martinez et al [35] and Morillo-Verduogo et al [38] did not record the blinding of participants and personnel; however, this was unlikely to influence the outcomes of those studies. The blinding of participants and personnel was not conducted in the Zuniga et al [38] study, as the graduate research assistant already knew the participants because they recruited, enrolled, and collected the baseline and follow-up data. This may likely have had an influence on the outcome of the study.

With regard to detection bias, the study by Anglada-Martinez et al [35] noted that the participants were not blinded to the measurement of the outcomes. This may have resulted in a Hawthorne effect, whereby the participants may have modified their behaviors because they were aware that their adherence to medication was being observed, thereby influencing the outcome of the study. Although the assessment forms were noted to be coded in the study by Roos et al [37], the blinding of the participants in the intervention group was not performed. These participants had 5 contact sessions in which they were educated on ischemic heart disease risk factors and the benefits of and methods for increasing physical activity levels. The participants in the control group experienced an increase in their pedometer step counts, which may have been linked to the fact that they were aware of their behavior (the Hawthorne effect). These factors were likely to influence the outcome of the Roos et al [37] study. Additionally, during the completion of the study, the intervention participants reported that wearing the pedometer motivated them to increase their activity levels [38]. The studies by Morillo-Verduogo et al [36] and Zuniga et al [38] failed to describe whether any form of blinding for the outcome assessor was performed.

\section{Attrition and Reporting Bias (Incomplete Outcome Data and Selective Reporting)}

In the study by Anglada-Martinez et al [35], there was a loss to follow-up of 20 participants. They were lost as a result of changing their addresses $(n=3)$, transitioning to the use of a non-Android or non-iOS device $(n=2)$, having incompatible Android and iOS operating systems $(n=6)$, dying $(n=1)$, not attending follow-ups $(n=7)$, and withdrawing from the study $(n=1)$. It was also noted that the adherence rates recorded with the use of the app did not correlate with the adherence rates that were recorded by analyzing the proportion of days in which participants took their medication. Some participants experienced problems such as their reminders not working properly (50\%), and some believed that the use of the app resulted in extra work (fourth month: $60.2 \%$; this decreased to $56.6 \%$ in the sixth month). Further, pending Medplan alerts, which appear during the day, disappear at midnight; hence, patients who took their medication before midnight were unable to confirm that they had done so after midnight (57.1\%) [35]. The prespecified outcomes of interest were however reported in accordance with the study protocols [35].

In the study by Morillo-Verdugo et al [36], there was loss to follow-up of 5 participants, and 1 died from causes that were beyond the scope of the study. It was also noted that because of the low number of patients with diabetes in the study, glycosylated hemoglobin was not included in the analysis. The prespecified outcomes of interest, such as reductions in cardiovascular risk indices based on Framingham scores, adherence to ART, and lifestyle modifications, were reported in accordance with the study protocol [36].

In the study by Roos et al [37], there were losses to follow-up in the control group at 6 months $(n=8)$ and 12 months $(n=10)$ and in the intervention group at 6 months $(n=3)$ and 12 months $(n=6)$. In the control group, 3 participants did not return for their second baseline assessment, and their baseline blood results were managed by imputing the mean value of the cohort's results. Additionally, some data were noted to be missing completely at random, and these were managed by imputing the last observation that was carried forward [37]. The prespecified outcomes of interest, such as perceived stress, physiological measures, physical activity, physical function capacity, biochemical measures, and Framingham risk scores, were reported in accordance with the study protocol [37].

In the study by Zuniga et al [38], 15 out of 25 patients participated in the baseline fasting blood tests, but only 1 completed the blood drawing for the collection of follow-up data. Therefore, the effects of the intervention on HIV or diabetes control could not be recorded. The reasons for losses to follow-up were not described; however, the reporting of prespecified outcomes of interest, such as the knowledge of diabetes and HIV and diabetes self-management activities, were reported in accordance with the study protocol [38].

\section{Discussion}

\section{Principal Findings}

This paper presents a narrative synthesis of mHealth interventions for treatment adherence and outcomes of care for CMD among adults with HIV. A total of 10 studies met the inclusion criteria and were included in the review. The majority of studies included in this review were conducted in high-income countries $(7 / 10,70 \%)[35,36,38,40-43]$, and only a handful of studies were from LMICs $(3 / 10,30 \%)$ [37,44,45].

Based on our review, the categories of the interventions that were used in the studies ranged from short messaging and telephone calls to wearable devices and smartphone and desktop web-based mobile apps. However, the two most common interventions that were provided to people living with HIV were short messaging and telephone calls. This finding is similar to those from another systematic review on the impact of mHealth 
chronic disease management on treatment adherence and patient outcomes, which found that $40 \%$ of the studies included in their review had used short messaging to track medication adherence in patients with chronic diseases [46]. We also found that across the different categories of interventions, there were no clear patterns in terms of consistency in the use of a particular intervention, as most studies $(9 / 10,90 \%)$ [35,36,38,40-45] assessed a combination of mHealth interventions.

Overall, authors reported that the use of mHealth interventions for treatment adherence and outcomes of care for CMD among adults living with HIV was effective. However, studies varied widely in terms of research questions, target groups, study outcomes, and settings $[36,37,41,43,44]$. The risk of bias varied from study to study. Of the 4 studies that assessed the risk of bias, 2 controlled for selection bias by randomization [35,37], and only 1 study performed the blinding of both participants and research personnel for the control of performance bias [37]. All 4 studies reported their prespecified outcomes of interest in accordance with their study protocols.

Most existing studies on mHealth interventions for people living with HIV have addressed ART adherence outcomes, and only a few have assessed mHealth interventions for CMD outcomes. In theory, the use of mHealth interventions to monitor treatment adherence and outcomes of care for both ART and CMD should make the process of care more efficient. However, research in this area is still very limited. This highlights the need to generate evidence to promote the use of integrated models of care for outcomes such as ART adherence and CMD outcomes. In addition, our findings from this review revealed that most studies did not report outcomes such as a reduction in the incidence of CMD, which should be the ultimate goal, given the increasing life expectancy of people living with HIV resulting from ART. However, this could be explained by the short follow-up periods that were used in these studies. We highlight the existing mHealth interventions that specifically target CMD outcomes among people living with HIV and draw attention to the gaps and opportunities in mHealth interventions for comorbid CMDs among people living with HIV. Furthermore, our review shows the paucity of well-designed RCTs in this research area. We also call attention to the disparities in the conduct of research on this topic. Globally, the WHO African region has been and remains to be the most severely affected by the HIV epidemic, as it accounts for more than two-thirds of the people living with HIV worldwide and nearly $3.7 \%$ adults (about 1 in every 25) living with HIV [47]. However, only 1 out of the 4 completed studies and 3 out of the 10 reviewed studies were conducted in an LMIC setting.

Although we purposefully used broad inclusion criteria to capture all studies evaluating any type of mHealth intervention for CMD among people living with HIV, we were limited by the low number of studies that met our inclusion criteria or reported on our predefined key outcomes. Furthermore, many of the studies that fit our inclusion criteria were old. Therefore, they may not have reflected the current state of the effectiveness of mHealth interventions. We also could not conduct a meta-analysis due to the heterogeneity of the included studies in terms of their methods and reported outcomes. However, it is important to point out that a number of clinical trials are underway, and their results can be incorporated in a follow-up review within the next few years. We recommend that future trials should focus on standardized outcomes for CMD to enable the conduction of a meta-analysis. We also suggest that future studies should consider using an integrated approach and a longer follow-up period in order to determine the long-term effects of mHealth interventions on outcomes of care.

\section{Conclusion}

Studies using mHealth interventions that specifically target CMD outcomes for people living with HIV are limited, particularly in Sub-Saharan Africa, where the burden of HIV is the greatest. In this review, although several of the mHealth interventions were found to be effective, there appears to be no clear pattern in the use of mHealth interventions for CMD outcomes. Short messaging was the most used intervention. More studies that assess the use and effectiveness of mHealth interventions other than short messaging, such as mobile apps and wearable health devices, are needed in this study area.

\section{Acknowledgments}

APK is supported by a European and Developing Countries Clinical Trials Partnership senior fellowship (grant TMA2017GSF-1962; Cardiometabolic Diseases Risk Evaluation and Reduction in African People Living with HIV Infection) through the South African Medical Research Council. OOO is supported by the Fogarty International Center of the National Institutes of Health under award number K43TW010704. The content of this review is solely the responsibility of the authors and does not necessarily represent the official views of the South African Medical Research Council or the National Institutes of Health.

\section{Conflicts of Interest}

None declared.

\section{Multimedia Appendix 1}

Search strings.

[PNG File, 887 KB-Multimedia Appendix 1]

\section{Multimedia Appendix 2}

Data extraction template [<xref ref-type="bibr" rid="ref35">35</xref $>-<x r e f$ ref-type="bibr" rid="ref38">38</xref>]. 
[PNG File, 1146 KB-Multimedia Appendix 2]

\section{References}

1. Trickey A, May MT, Vehreschild J, Obel N, Gill MJ, Crane H, Antiretroviral Therapy Cohort Collaboration (ART-CC). Cause-specific mortality in HIV-positive patients who survived ten years after starting antiretroviral therapy. PLoS One 2016 Aug 15;11(8):e0160460. [doi: 10.1371/journal.pone.0160460] [Medline: 27525413]

2. Petersen M, Yiannoutsos CT, Justice A, Egger M. Observational research on NCDs in HIV-positive populations: conceptual and methodological considerations. J Acquir Immune Defic Syndr 2014 Sep 01;67 Suppl 1(0 1):S8-S16 [FREE Full text] [doi: 10.1097/QAI.0000000000000253] [Medline: 25117964]

3. Poorolajal J, Hooshmand E, Mahjub H, Esmailnasab N, Jenabi E. Survival rate of AIDS disease and mortality in HIV-infected patients: a meta-analysis. Public Health 2016 Oct;139:3-12. [doi: 10.1016/j.puhe.2016.05.004] [Medline: 27349729]

4. Hoffmann CJ, Fielding KL, Johnston V, Charalambous S, Innes C, Moore RD, et al. Changing predictors of mortality over time from cART start: implications for care. J Acquir Immune Defic Syndr 2011 Nov 01;58(3):269-276 [FREE Full text] [doi: 10.1097/QAI.0b013e31823219d1] [Medline: 21876447]

5. Grinsztejn B, Luz PM, Pacheco AG, Santos DVG, Velasque L, Moreira RI, et al. Changing mortality profile among HIV-infected patients in Rio de Janeiro, Brazil: shifting from AIDS to non-AIDS related conditions in the HAART era. PLoS One 2013;8(4):e59768. [doi: 10.1371/journal.pone.0059768] [Medline: 23577074]

6. Triant VA. Cardiovascular disease and HIV infection. Curr HIV/AIDS Rep 2013 Sep;10(3):199-206 [FREE Full text] [doi: 10.1007/s11904-013-0168-6] [Medline: 23793823]

7. Kazooba P, Kasamba I, Mayanja BN, Lutaakome J, Namakoola I, Salome T, et al. Cardiometabolic risk among HIV-POSITIVE Ugandan adults: prevalence, predictors and effect of long-term antiretroviral therapy. Pan Afr Med J 2017 May 15;27:40 [FREE Full text] [doi: 10.11604/pamj.2017.27.40.9840] [Medline: 28761616]

8. Kiage JN, Heimburger DC, Nyirenda CK, Wellons MF, Bagchi S, Chi BH, et al. Cardiometabolic risk factors among HIV patients on antiretroviral therapy. Lipids Health Dis 2013 Apr 10;12:50 [FREE Full text] [doi: 10.1186/1476-511X-12-50] [Medline: 23575345]

9. Sogarwa R, Mehra S. Approaches to address NCD among PLHIV in low and middle income counties. J AIDS Clin Res 2015;06(06):1000472 [FREE Full text] [doi: 10.4172/2155-6113.1000472]

10. Nigatu T, Oldenburg B, Elliott J, Setswe G, Woldegiorgis MA. The incidence of cardiovascular disease, cancer and type 2 diabetes comorbidities in HIV infection: A systematic review. J Nurs Educ Pract 2013 Jan 09;3(7):58-67. [doi: 10.5430/jnep.v3n7p58]

11. De Wit S, Sabin CA, Weber R, Worm SW, Reiss P, Cazanave C, Data Collection on Adverse Events of Anti-HIV Drugs (D:A:D) study. Incidence and risk factors for new-onset diabetes in HIV-infected patients: the Data Collection on Adverse Events of Anti-HIV Drugs (D:A:D) study. Diabetes Care 2008 Jun;31(6):1224-1229 [FREE Full text] [doi: 10.2337/dc07-2013] [Medline: 18268071]

12. Haregu TN, Oldenburg B, Setswe G, Elliott J. Magnitude of diabetes comorbidity among people living with HIV: A systematic review. Int J Diabetes Res 2012 Dec 7;1(5):81-86 [FREE Full text] [doi: 10.5923/j.diabetes.20120105.02]

13. Brown TT, Cole SR, Li X, Kingsley LA, Palella FJ, Riddler SA, et al. Antiretroviral therapy and the prevalence and incidence of diabetes mellitus in the multicenter AIDS cohort study. Arch Intern Med 2005 May 23;165(10):1179-1184. [doi: 10.1001/archinte.165.10.1179] [Medline: 15911733 ]

14. Chow FC, Regan S, Feske S, Meigs JB, Grinspoon SK, Triant VA. Comparison of ischemic stroke incidence in HIV-infected and non-HIV-infected patients in a US health care system. J Acquir Immune Defic Syndr 2012 Aug 01;60(4):351-358 [FREE Full text] [doi: 10.1097/QAI.0b013e31825c7f24] [Medline: 22580566]

15. Tseng ZH, Secemsky EA, Dowdy D, Vittinghoff E, Moyers B, Wong JK, et al. Sudden cardiac death in patients with human immunodeficiency virus infection. J Am Coll Cardiol 2012 May 22;59(21):1891-1896 [FREE Full text] [doi: 10.1016/j.jacc.2012.02.024] [Medline: 22595409]

16. Butt AA, Chang C, Kuller L, Goetz MB, Leaf D, Rimland D, et al. Risk of heart failure with human immunodeficiency virus in the absence of prior diagnosis of coronary heart disease. Arch Intern Med 2011 May 25;171(8):737-743 [FREE Full text] [doi: 10.1001/archinternmed.2011.151] [Medline: 21518940]

17. Currier JS, Taylor A, Boyd F, Dezii CM, Kawabata H, Burtcel B, et al. Coronary heart disease in HIV-infected individuals. J Acquir Immune Defic Syndr 2003 Aug 01;33(4):506-512. [doi: 10.1097/00126334-200308010-00012] [Medline: 12869840]

18. Obel N, Thomsen HF, Kronborg G, Larsen CS, Hildebrandt PR, Sørensen HT, et al. Ischemic heart disease in HIV-infected and HIV-uninfected individuals: a population-based cohort study. Clin Infect Dis 2007 Jul 15;44(12):1625-1631. [doi: 10.1086/518285] [Medline: 17516408]

19. Triant VA, Lee H, Hadigan C, Grinspoon SK. Increased acute myocardial infarction rates and cardiovascular risk factors among patients with human immunodeficiency virus disease. J Clin Endocrinol Metab 2007 Jul;92(7):2506-2512 [FREE Full text] [doi: 10.1210/jc.2006-2190] [Medline: 17456578]

20. Mdege ND, Shah S, Ayo-Yusuf OA, Hakim J, Siddiqi K. Tobacco use among people living with HIV: analysis of data from Demographic and Health Surveys from 28 low-income and middle-income countries. Lancet Glob Health 2017 Jun;5(6):e578-e592 [FREE Full text] [doi: 10.1016/S2214-109X(17)30170-5] [Medline: 28495263] 
21. Saitz R. Clinical practice. Unhealthy alcohol use. N Engl J Med 2005 Feb 10;352(6):596-607. [doi: 10.1056/NEJMcp042262] [Medline: 15703424$]$

22. Lasica JD. The Mobile Generation: Global Transformations At the Cellular Level: A report of the Fifteenth annual Aspen Institute Roundtable on Information Technology. Washington, DC: Aspen Institute Communications and Society Program; 2007.

23. Catalani C, Philbrick W, Fraser H, Mechael P, Israelski DM. mHealth for HIV Treatment \& Prevention: A Systematic Review of the Literature. Open AIDS J 2013 Aug 13;7:17-41 [FREE Full text] [doi: 10.2174/1874613620130812003] [Medline: 24133558]

24. Hirsch-Moverman Y, Daftary A, Yuengling KA, Saito S, Ntoane M, Frederix K, et al. Using mHealth for HIV/TB treatment support in Lesotho: Enhancing patient-provider communication in the START Study. J Acquir Immune Defic Syndr 2017 Jan 01;74 Suppl 1(Suppl 1):S37-S43 [FREE Full text] [doi: 10.1097/QAI.0000000000001202] [Medline: 27930610]

25. Devi BR, Syed-Abdul S, Kumar A, Iqbal U, Nguyen PA, Li YCJ, et al. mHealth: An updated systematic review with a focus on HIV/AIDS and tuberculosis long term management using mobile phones. Comput Methods Programs Biomed 2015 Nov;122(2):257-265. [doi: 10.1016/j.cmpb.2015.08.003] [Medline: 26304621]

26. Tufts KA, Johnson KF, Shepherd JG, Lee JY, Ajzoon MSB, Mahan LB, et al. Novel interventions for HIV self-management in African American women: a systematic review of mHealth interventions. J Assoc Nurses AIDS Care 2015;26(2):139-150. [doi: 10.1016/j.jana.2014.08.002] [Medline: 25283352]

27. Horvath T, Azman H, Kennedy GE, Rutherford GW. Mobile phone text messaging for promoting adherence to antiretroviral therapy in patients with HIV infection. Cochrane Database Syst Rev 2012 Mar 14;3(3):CD009756 [FREE Full text] [doi: 10.1002/14651858.CD009756] [Medline: 22419345]

28. Park LG, Howie-Esquivel J, Dracup K. A quantitative systematic review of the efficacy of mobile phone interventions to improve medication adherence. J Adv Nurs 2014 Sep;70(9):1932-1953. [doi: 10.1111/jan.12400] [Medline: 24689978]

29. van Velthoven MHMMT, Brusamento S, Majeed A, Car J. Scope and effectiveness of mobile phone messaging for HIV/AIDS care: a systematic review. Psychol Health Med 2013;18(2):182-202. [doi: 10.1080/13548506.2012.701310] [Medline: 22788357]

30. Mbuagbaw L, Mursleen S, Lytvyn L, Smieja M, Dolovich L, Thabane L. Mobile phone text messaging interventions for HIV and other chronic diseases: an overview of systematic reviews and framework for evidence transfer. BMC Health Serv Res 2015 Jan 22;15(1):33 [FREE Full text] [doi: 10.1186/s12913-014-0654-6] [Medline: 25609559]

31. PRISMA. PRISMA Transparent Reporting of Systematic Reviews and Meta-Analyses. URL: http://www. prisma-statement.org/ [accessed 2021-05-27]

32. mHealth: New horizons for health through mobile technologies. World Health Organization. URL: https://www.who.int/ goe/publications/goe mhealth web.pdf [accessed 2021-05-27]

33. Ouzzani M, Hammady H, Fedorowicz Z, Elmagarmid A. Rayyan-a web and mobile app for systematic reviews. Syst Rev 2016 Dec 05;5(1):210 [FREE Full text] [doi: 10.1186/s13643-016-0384-4] [Medline: 27919275]

34. Module 4: Selecting studies and collecting data. The Cochrane Collaboration. URL: http://training.cochrane.org/resource/ data-collection-forms-intervention-reviews [accessed 2021-05-27]

35. Anglada-Martínez H, Martin-Conde M, Rovira-Illamola M, Sotoca-Momblona JM, Sequeira E, Aragunde V, et al. Feasibility and preliminary outcomes of a web and smartphone-based medication self-management platform for chronically ill patients. J Med Syst 2016 Apr;40(4):99. [doi: 10.1007/s10916-016-0456-y] [Medline: 26872781]

36. Morillo-Verdugo R, Robustillo-Cortés MDLA, Martín-Conde MT, Callejón-Callejón G, Cid-Silva P, Moriel-Sánchez C, et al. Effect of a structured pharmaceutical care intervention versus usual care on cardiovascular risk in HIV patients on antiretroviral therapy: INFAMERICA Study. Ann Pharmacother 2018 Nov;52(11):1098-1108. [doi: 10.1177/1060028018778045] [Medline: 29808711]

37. Roos R, Myezwa H, van Aswegen H, Musenge E. Effects of an education and home-based pedometer walking program on ischemic heart disease risk factors in people infected with HIV: a randomized trial. J Acquir Immune Defic Syndr 2014 Nov 01;67(3):268-276. [doi: 10.1097/QAI.0000000000000299] [Medline: 25140908]

38. Zuñiga J, García AA, Silva L, Park JM, Barrera Y. Pilot test of an educational intervention to improve self-management of diabetes in persons living with HIV. Pilot Feasibility Stud 2019 Sep 07;5:111 [FREE Full text] [doi: 10.1186/s40814-019-0495-5] [Medline: 31516728]

39. Higgins JPT, Altman DG, Gøtzsche PC, Jüni P, Moher D, Oxman AD, Cochrane Bias Methods Group, Cochrane Statistical Methods Group. The Cochrane Collaboration's tool for assessing risk of bias in randomised trials. BMJ 2011 Oct 18;343:d5928 [FREE Full text] [doi: 10.1136/bmj.d5928] [Medline: 22008217]

40. Grinspoon S. Study of lifestyle modification in HIV lipodystrophy. National Institutes of Health, U.S. National Library of Medicine, ClinicalTrials.gov. 2006. URL: https://clinicaltrials.gov/ct2/show/NCT00111358 [accessed 2021-05-27]

41. Jaggers JR, Dudgeon W, Blair SN, Sui X, Burgess S, Wilcox S, et al. A home-based exercise intervention to increase physical activity among people living with HIV: study design of a randomized clinical trial. BMC Public Health 2013 May 24;13(1):502 [FREE Full text] [doi: 10.1186/1471-2458-13-502] [Medline: 23706094] 
42. Brooke H. iSTEP - an mHealth physical activity and diet intervention for persons with HIV. National Institutes of Health, U.S. National Library of Medicine, ClinicalTrials.gov. 2017. URL: https://clinicaltrials.gov/ct2/show/NCT03123731 [accessed 2021-05-28]

43. Dodson S, Klassen KM, McDonald K, Millard T, Osborne RH, Battersby MW, et al. HealthMap: a cluster randomised trial of interactive health plans and self-management support to prevent coronary heart disease in people with HIV. BMC Infect Dis 2016 Mar 05;16(1):114 [FREE Full text] [doi: 10.1186/s12879-016-1422-5] [Medline: 26945746]

44. Oduor E, Nyota T, Wachira C, Osebe S, Remy SL, Walcott A. Medication management companion (MMC) for a rural Kenyan community. In: CSCW '18: Companion of the 2018 ACM Conference on Computer Supported Cooperative Work and Social Computing. 2018 Oct 30 Presented at: CSCW '18: Computer Supported Cooperative Work and Social Computing; November 3-7, 2018; Jersey City, NJ, USA p. 145-148. [doi: 10.1145/3272973.3274041]

45. Kengne AP. Mobile phone SMS for adherence support for hypertension in South African adults in care for HIV infection. Pan African Clinical Trials Registry. 2019. URL: https://pactr.samrc.ac.za/TrialDisplay.aspx?TrialID=4711 [accessed 2021-05-28]

46. Hamine S, Gerth-Guyette E, Faulx D, Green BB, Ginsburg AS. Impact of mHealth chronic disease management on treatment adherence and patient outcomes: a systematic review. J Med Internet Res 2015 Feb 24;17(2):e52 [FREE Full text] [doi: 10.2196/jmir.3951] [Medline: 25803266]

47. Deaths. World Health Organization. URL: https://www.who.int/gho/hiv/en/ [accessed 2020-07-07]

\author{
Abbreviations \\ ART: antiretroviral therapy \\ CMD: cardiometabolic disease \\ LMIC: low- and middle-income country \\ mHealth: mobile health \\ PRISMA: Preferred Reporting Items for Systematic reviews and Meta-Analyses \\ RCT: randomized controlled trial \\ WHO: World Health Organization
}

Edited by L Buis; submitted 16.05.20; peer-reviewed by J Seitz, C Wu; comments to author 11.07.20; revised version received 13.08.20;
accepted 16.04.21; published 09.06.21
Please cite as:
Odukoya OO, Ohazurike C, Akanbi M, O'Dwyer LC, Isikekpei B, Kuteyi E, Ameh IO, Osadiaye O, Adebayo K, Usinoma A, Adewole
A, Odunukwe N, Okuyemi K, Kengne AP
mHealth Interventions for Treatment Adherence and Outcomes of Care for Cardiometabolic Disease Among Adults Living With HIV:
Systematic Review
JMIR Mhealth Uhealth $2021 ; 9(6): e 20330$
URL: $\underline{\text { https://mhealth.jmir.org/2021/6/e20330 }}$
doi: $10.2196 / 20330$
PMID:

(C) Oluwakemi Ololade Odukoya, Chidumga Ohazurike, Maxwell Akanbi, Linda C O'Dwyer, Brenda Isikekpei, Ewemade Kuteyi, Idaomeh O Ameh, Olanlesi Osadiaye, Khadijat Adebayo, Adewunmi Usinoma, Ajoke Adewole, Nkiruka Odunukwe, Kola Okuyemi, Andre Pascal Kengne. Originally published in JMIR mHealth and uHealth (https://mhealth.jmir.org), 09.06.2021. This is an open-access article distributed under the terms of the Creative Commons Attribution License (https://creativecommons.org/licenses/by/4.0/), which permits unrestricted use, distribution, and reproduction in any medium, provided the original work, first published in JMIR mHealth and uHealth, is properly cited. The complete bibliographic information, a link to the original publication on https://mhealth.jmir.org/, as well as this copyright and license information must be included. 